\title{
Exploring Teachers' PCK for Computational Thinking in Context
}

\author{
Sabiha Yeni \\ Leiden Institute of Advanced \\ Computer Science \\ Netherlands \\ s.yeni@liacs.leidenuniv.nl
}

\author{
Natasa Grgurina \\ Radboud University \& Groningen \\ University \\ Netherlands \\ n.grgurina@rug.nl
}

\author{
Felienne Hermans \\ Leiden Institute of Advanced \\ Computer Science \\ Netherlands \\ f.f.j.hermans@liacs.leidenuniv.nl
}

\author{
Jos Tolboom \\ SLO, Netherlands Institute for \\ Curriculum Development \\ Netherlands \\ j.tolboom@slo.nl
}

\author{
Erik Barendsen \\ Radboud University \& Open \\ University \\ Netherlands \\ erik.barendsen@ru.nl
}

\begin{abstract}
There is growing attention for integrating Computational Thinking (CT) into various subjects across the K-12 curriculum with a concomitant increase of interest in investigating teachers' pedagogical content knowledge (PCK) regarding CT. This study is part of a bigger project focusing on defining the learning trajectories for $\mathrm{CT}$ integration into the $\mathrm{K}-12$ curriculum. In particular, the present study focused on eliciting the pedagogical content knowledge and attitude of teachers with respect to the integration of $\mathrm{CT}$ in various disciplines. To this end, we implemented six different case studies by integrating CT into six different subjects: science, traffic, language, biology, geography, and physics. Two primary and four secondary school teachers were involved in the study. After the lesson series was completed in schools, we conducted interviews with teachers to understand their PCK on CT integration, attitudes toward CT integrated lessons, and the barriers teachers faced during CT integrated lessons. Our results indicate that compared to standard instructional activities, students can go deeper and understand the subject content better in CT integrated lessons, also students can use the power of digital technologies to solve subject-related problems. On the other hand, teachers pointed out that students and teachers need to be more capable of technical knowledge and skills to accomplish tasks.
\end{abstract}

\section{CCS CONCEPTS}

- Social and professional topics $\rightarrow$ Computer science education, $\mathrm{K}-12$ education .

\section{KEYWORDS}

Computational thinking, integration, $\mathrm{K}-12$, curriculum, teacher, pedagogical content knowledge

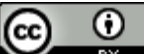

This work is licensed under a Creative Commons Attribution International 4.0 License.

WiPSCE '21, October 18-20, 2021, Virtual Event, Germany

(c) 2021 Copyright held by the owner/author(s).

ACM ISBN 978-1-4503-8571-8/21/10.

https://doi.org/10.1145/3481312.3481320
}

\section{ACM Reference Format:}

Sabiha Yeni, Natasa Grgurina, Felienne Hermans, Jos Tolboom, and Erik Barendsen. 2021. Exploring Teachers' PCK for Computational Thinking in Context. In The 16th Workshop in Primary and Secondary Computing Education (WiPSCE '21), October 18-20, 2021, Virtual Event, Germany. ACM, New York, NY, USA, 10 pages. https://doi.org/10.1145/3481312.3481320

\section{INTRODUCTION}

There is an increasing interest in integrating CT into all courses throughout the K-12 curriculum. The skills, knowledge, and abilities required for success in modern society have evolved with the developing technological developments. The term CT started from a way of how computer scientists think, but in today's society, it has evolved into a broad application spectrum for everyone who try to find their way in the technological world and solve problems effectively. Jeannette Wing [29] coined the CT term in this context, and stated that besides the standard types of literacy, such as mathematical, engineering and reading literacy. Even children that will not become programmers are expected to acquire some CT competencies such as the ability to solve problems in daily life, break down complex problems into components, and generalize solutions.

\section{BACKGROUND AND RELATED WORK \\ 2.1 Integrating CT Skills into Different Contexts}

Papert suggested a goal of introducing computational thinking by using a computer to solve problems in a way that allows people better to analyze and explain the problems, solutions and connections between them [17]. Wing [29], who promoted and popularized the notion of CT, defined it as "... the thought processes involved in formulating problems and their solutions so that the solutions are represented in a form that can be effectively carried out by an information-processing agent [...]. These solutions can be carried out by any processing agent, whether human, computer, or a combination of both" (Cuny et al., cited in [28], p.11). Following Wing's seminal paper [29], several definitions of CT were developed emphasizing various aspects of CT [6][19][26].

To date, a number of efforts have focused on integrating CT in K-12 classrooms. Voogt et al. [25] explain that CT originated within the field of computer science but programming is only one of 
many instantiations of CT. In fact, CT can be developed in multiple contexts and within subject areas beyond computer science (e.g., science, mathematics, music, humanity, etc.). There are already numerous examples of CT playing a role in the learning of the subject matter in various disciplines outside of the computer science (CS) education [9] [18] [20] [27].

While learning CT concepts in the context of stand-alone computer science courses is valuable, nevertheless much like technology integration, CT is an interdisciplinary initiative that can help support existing standards and subjects in the curriculum [16]. Given the cross-curricular focus of CT, all teachers at the K-8 level should be responsible for introducing and reinforcing CT skills, recognizing and highlighting CT skills already integrated in their teaching, and using CT-related computing tools and vocabulary where appropriate to describe problems and solutions [4]. Thereby, it is important to discuss teachers' PCK on CT integrated various disciplines in K-12 curriculum, which helps to understand how teachers integrate CT-related concepts, tools, and practices into specific subject related content and pedagogy to address CT integrated curricular standards.

\subsection{PCK Framework}

The PCK concept has been introduced by Shulman [21] and refers to "the ways of representing and formulating the subject that make it comprehensible to others" (p. 9). Magnusson et al. [14] adds additional components to Shulman's definition of the construct of PCK. Four of the Magnusson's components correspond to the following elements of content-specific pedagogy [14]: (M1) goals and objectives for teaching a specific topic in the curriculum, (M2) students' understanding of this topic, (M3) instructional strategies concerning this topic, and (M4) ways to assess students' understanding of this topic [14]. Because of their pedagogical completeness and simplicity, Barendsen and Henze used Magnusson et al.'s components to characterize elements of content-specific pedagogy and the corresponding PCK elements [3]. The framework of PCK has provided a unifying lens for researchers aiming to understand teacher knowledge for effective use of instructional materials, strategies and practices throughout the curriculum. According to van Driel and Berry [24], having a good PCK means that teachers have several representations of the most commonly taught topics within a certain subject.

Some research studies have already attempted to define the PCK needed to teach CS concepts in computer science curricula. For instance, Hubwieser et al. [12] aimed to figure out what skills are needed to teach stand-alone computer science courses. The focus was on subject matter content knowledge related to computer science and PCK. However, this study was not situated within the subject-related context. Ioannou and Angeli [13] described the design of technology-enhanced lessons for teaching computer science concepts. The purpose of this work was to illustrate examples where the TPACK framework could be used to guide the design and delivery of lessons focusing on fundamental computer science concepts. This set of studies is useful in thinking about the knowledge and skills required to teach CS concepts in stand-alone computer science curricula. Yet, they focus on CS teachers with strong disciplinary background in computer science. Further, although CT and computer science are intertwined, they are not equivalent. Further, $\mathrm{CT}$ concepts can be applied in a variety of content areas beyond computer science. So far studies examining PCK in relation to CT integration into specific subject-related context have been absent.

\subsection{PCK of CT Integration to K-12}

Promoting CT in K-12 settings is challenging because few teachers have the knowledge and skills to integrate CT in school curricula [4]. Helping teachers develop an understanding of CT and how it relates to their curricular context is a key step in successfully incorporating CT into K-12 education [31]. Many schools around the world have started incorporating CT in their curriculum, meanwhile struggling with the question how to do so in a systematic and effective manner, as well as how to support their teachers. As GalEzer and Stephenson [8] pointed out, having a curriculum is crucial, but preparing teachers to teach the curriculum is also critical. PCK provides a useful framework for studying teacher knowledge in relation to $\mathrm{CT}$, because computational tools play a central role in CT- related concepts and practices; they are frequently used as a means for solving a problem or teaching a CT-related practice [1].

With respect to CT knowledge of pre-service teachers, Bower and Falkner [5] found that most participants were unaware of the term CT and mistakenly considered CT as the basic use of technology. When asked to identify pedagogical strategies for helping students develop CT, participants did not have specific or clear ideas and simply noted the need to have students use technology. Further, many participants provided general pedagogical strategies that were not specific to CT such as group work and direct instruction. When asked to identify computing tools that can support the learning of CT, most participants suggested tools that had no specific relation to CT while some focused-on programming tools and robotics alone. Finally, the majority of the participants were not confident that they could integrate CT in their teaching [5].

The PCK framework could serve as a useful model for integrating CT where the related ideas are connected within the subject matter and pedagogical approaches teachers will teach in their future classrooms [30]. Angeli et al. [1] provided a conceptualization of TPACK for the construct of CT in CS context. However, this conceptualization focuses on what teachers need to know and be able to do in order to teach stand-alone CT-courses aligned with a CT framework proposed by the authors. As such, in the conceptualization provided by Angeli and colleagues, content knowledge (CK) focuses on knowledge of distinct CT constructs. The result of this study is useful for teachers who teach complete curricula focusing on computer science concepts and CT specifically. Our study focuses on all disciplines not only CS course. Because integrating CT knowledge and skills across the curriculum is essential for helping students understand how to use computing tools to represent knowledge, solve problems, create and discover new questions within specific disciplines [10].

Mouza et al. [16] and Yang et al.[32] explicated the construct of TPACK in relation to CT, focusing on what all teachers need to know and be able to do in order to use CT as a means for exploring disciplinary content. Towards this end they focused on pre-service teachers' ability to understand how CT-related concepts, computing tools, and practices can be combined with disciplinary content and 
pedagogical strategies to promote meaningful student outcomes in specific contexts. Unlike this study, our study focuses on 'in-service' teachers' CT integration into various disciplines and 'their PCK and perceptions regarding CT integration'.

These studies provide a good starting point for understanding teachers' knowledge and skills of CT but they are not situated for in-service teachers and the $\mathrm{CT}$ integrated subject related context. In this study, researchers conducted an explorative study aimed at discovering teachers' $\mathrm{PCK}$, perceptions, beliefs and hindrances around Computational Thinking integration into various disciplines of K-12 curriculum. We implemented six different case studies with teachers for integrating CT into their own disciplines in primary and secondary school level. We analyzed the interviews of teachers after they accomplished their CT integrated lessons to understand current state and problems of teachers integrating CT in different contexts. The following research questions formed the basis of this study:(1) How can teachers' PCK for teaching CT integrated subjects be described? (2) What are the attitudes of teachers toward CT integrated lessons? (3) What are the challenges faced by teachers during CT integrated lessons?

\section{METHODOLOGY}

This study is part of a bigger project [2] focusing on defining the learning trajectories for $\mathrm{CT}$ integration into K-12 curriculum. In particular, this study focused on eliciting the pedagogical content knowledge and attitude of teachers with respect to the integration of CT in various disciplines of the K-12 curriculum. To this end, we carried out case studies in several primary and secondary schools and we interviewed with teachers. The following paragraphs describe the research design, participants, data collection, and data analysis process.

\subsection{Research Design}

This study was designed as a case study. Six different cases were implemented in six different schools, two of them are primary and four of them are secondary schools. The participating teachers, one from each school, attended a workshop where they were shown CT concepts and examples of lessons that CT integrated with several disciplines across the curriculum, such as science, humanities, and languages. Then, each teacher worked with the researchers individually and developed a lesson series about a topic they planned to teach anyway, as well as with the level and type of CT they felt comfortable with (Table 1).

Case 1: In this case, the students learned about the cell division in the primary school. During the two introductory lessons, they learned about the theory of cell division, watched subject related videos and observed cells under a digital microscope. In the subsequent two lessons, students worked in pairs on a practical assignment: they wrote down all they knew about cell division, they described the corresponding algorithm and developed computational models of cell division in Scratch. During programming, their class teacher and their programming teacher were helping them when necessary. At the end of the last lesson, each pair of students presented their program in front of the class.

Case 2: In this primary school, the students were learning about self-driving cars and corresponding ethical questions. In the first lesson, the students drew a car with sensors needed to participate in traffic safely, and were asked to write a short algorithm for each sensor. Additionally, they were asked to program a m-Bot with an ultrasonic distance sensor by arranging a set of given commands in a correct order. In the second lesson, the students discussed the advantages of self-driving cars and a number of ethical dilemma's arising from traffic situations. Additionally, they were asked to extend their $\mathrm{m}$-Bot program to have it follow a line and play a sound - again by putting the given program blocks in the correct order.

Case 3: In the English course, students studied to apply the acquired grammar and vocabulary in their digital stories. In the introduction lessons they learned to ask and answer questions in the present simple tense about themselves. They learned specific words related to clothing, hobbies, date, time, food and drink. In the subsequent two lessons, students were asked to create their own digital stories. In the story, they introduced themselves and described their clothing style, school/city, hobbies, likes and dislikes. Students are received an explanation about goals of the digital story and they made planning. Students worked in pairs and created their storyboards by writing out the scripts of the digital story. They received feedback from teacher about the scripts. Then students created their digital stories in Scratch. They recorded their voices and added them to their digital stories in order to vocalize the dialogues of the characters in the story. During the programming, their class teacher, researcher and their friends experience in programming helped students when necessary (Figure 1).
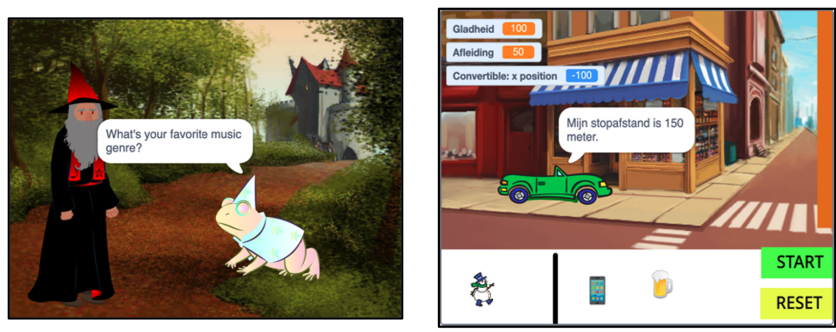

Figure 1: Introduce yourself (English)

Figure 2: Stop distance (Physics)

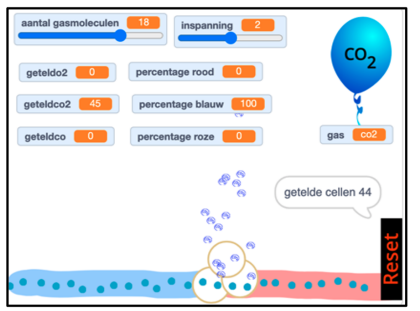

Figure 3: Gas exchange (Biology)

Case 4:The students were learning about the Koppen climate classification. During three lessons, they learned about the characteristics of the main climate groups and how to determine the climate type from temperature and precipitation data. They were then asked to write down that climate determination process in the 
Table 1: CT integrated various disciplines in $\mathrm{K}-12$ curriculum

\begin{tabular}{llllll}
\hline C & Subject & Context & Grade & Location & N \\
\hline 1 & Science & Cell division & 7 & Physical & 20 \\
2 & Traffic & Ethical dilemmas & 7 & Physical & 25 \\
3 & English & Introduce yourself & 9 & Physical & 44 \\
4 & Geography & Climates & 9 & Online & 19 \\
5 & Physics & Stop distance & 9 & Physical & 17 \\
6 & Biology & Gas exchange & 9 & Physical & 36 \\
\hline
\end{tabular}

form of a decision tree. Due to Corona measures, the lessons were carried out as online lessons.

Case 5: The students were learning about the stopping distance of a moving vehicle which depends on the road conditions and the reaction speed of the driver. The first lesson was dedicated to theory. In the subsequent two lessons, the students used a simple model in Scratch provided by their teacher and researchers to explore the influence of icy road, drinking and distraction on the stopping distance. Additionally, the students were asked to adjust the model's program code (Figure 2).

Case 6: The students were learning about the human body, and in particular, about gas exchange. The researchers provided a simple gas exchange model in Scratch. During three lessons, the students were using it to learn about the oxygen saturation of blood which depends on the type and quantity of the gas being inhaled and the exertion rate. Additionally, the students were asked to adjust the model's program code (Figure 3).

\subsection{Data Collection and Analysis}

After the lesson series were completed in schools, we conducted six interviews individually with teachers. The interview followed a semi-structured interview protocol. Each interview lasted around half an hour. All interviews were recorded for further analysis. The interview questions cover the four PCK elements of Magnusson et al. [14] and some additional questions related to attitudes of teachers and barriers which they faced during the lessons. They were also asked to compare their experiences teaching the lessons during the project to their standard manner of teaching the same subject matter, i.e., without employing CT.

The data obtained from the interviews were analyzed by a qualitative inductive data analysis in order to discover the views of teachers regarding to $\mathrm{CT}$ integration into various disciplines. We used Atlas.ti software as qualitative data analysis tool for coding our data. The analysis of the interviews was carried out in four phases. The content of transcripts were categorized according to research questions. Three main themes were defined based on the research questions of the project, closely in line with the topics of the interview protocol: (1) teachers' PCK (2) teachers' perceptions about CT integration, (3) difficulties and improvement suggestions. For the first theme (teachers' PCK), we used the four PCK elements as the analytical framework for coding the data [14].

The three phases of coding consisted of open coding, axial coding and selective coding [22]. The open coding phase was initially conducted on two interviews to define a number of basic labels within these three main themes. During this phase, the interview
Table 2: Demographics of participants

\begin{tabular}{llllll}
\hline Code & Gender & Age & Grade & Subject & Exp $^{*}$ \\
\hline T1 & M & 51 & 7 & Primary & 17 \\
T2 & M & 38 & $6,7,8$ & Primary & 13 \\
T3 & M & 35 & 9 & English & 11 \\
T4 & M & 66 & $9,10,12,13$ & Geography & 32 \\
T5 & M & 33 & $9,10,11$ & Science & 13 \\
T6 & M & 57 & All & Biology & 17 \\
\hline \multicolumn{7}{c}{ *Experience as years }
\end{tabular}

transcripts were fully read and the labels were extracted from the transcripts and linked to themes. Due to the inductive approach, open coding per each theme resulted in a broad identification of ideas and views. Then, in the axial coding phase, each label was reviewed and the labels were grouped and related labels were combined under new categories. Finally, in the selective coding phase, related categories were selected and grouped as new sub-themes.

\subsection{Participants}

For our study, we aimed to include teachers who are willing to integrate CT into their own lessons voluntarily. The participants of the study are six teachers (Table 2). Two of them are primary school teachers and four of them are secondary school teachers who teach different subjects. Their age range is changing between 33 and 66, average age is 47 . All of them are male participants and experienced in teaching more than 10 years. Two primary school teachers, T1 and $\mathrm{T} 2$ are sub-project leaders at digital literacy projects. One of the teachers, T4 formerly worked as computer science (CS) teacher.

\section{RESULTS}

\subsection{Knowledge about Goals and Objectives (M1)}

We concluded that the teachers' knowledge about learning objectives can be divided into two main categories: subject-related learning objectives and CT-related learning objectives.

4.1.1 Subject related learning objectives. Six cases carried out in this study have different learning objectives. This category emphasizes the objectives for learning or understanding the subject related concepts. With respect to the subject related learning objectives, the primary school teacher (T1) told that "The children learned about the concept of cell division [...], to name the parts of the cell, in part, at group 7 level. And I think those were mainly the biggest professional goals." T2 explained the learning objectives like "The lesson goal was to teach them that a programmer can sometimes also have to deal with ethical dilemmas. Programmers don't only type in code, but they also have to think about these kinds of bigger problems. And also have to come up with solutions for this. This was done on the basis of those self-driving cars." T3 focused on "Basically they were able to act and answer questions in the present simple. They talk about their hobbies, date, time, places and ask questions about them and use the vocabulary that they learned within the grammar or the stories" T4 summarized the learning objectives as "We talked about the climate, and for climate you have a number of indicators to indicate to what kind of climate something belongs: a certain temperature, 
precipitation, heat, cold." T5 aimed for students "to be concerned with the stopping distance, and to understand which factors actually influence the stopping distance? This has to do with the responsiveness and the braking distance." T6 told the subject related learning goals as "they were in biology; they could see that there was gas exchange".

4.1.2 CT related learning objectives. This category emphasizes the objectives for learning or understanding the CT related concepts, practices and perspectives. It is noticeable that all teachers emphasized only CT concepts which include the technology activities as learning goals. None of the teachers explained CT learning objectives which based on $\mathrm{CT}$ practice (such as abstraction, algorithmic thinking, etc.) or CT perspectives (understandings about the technological world around them). Teachers emphasized mainly these CT related learning objectives: "We did CT integration through the topic of cell division. Children have to depict that in an animation or a movie or a game in Scratch. Most of the time it was animations what I saw." [T1] "The CT goal of lesson was for the children to learn what sensors are and how to program sensors." [T2] "Creating an animation story and that based on the Scratch program, so using the steps you need in scratch so basically creating the algorithm in scratch to create a story" [T3] "We asked students to make a decision tree for classifying climates" [T4] "We mainly asked if-then questions. Or if you adjust this, what actually happens with the braking distance? They have to adjust values themselves in Scratch." [T5] "There was gas exchange, so blood, air, that they could make that visible by means of that computer animation, or what do you call that, that game. Some saw it as a game, others as a programming assignment, others as assignments." [T6]

\subsection{Knowledge about Students' Understanding and Performance (M2)}

We categorized teachers' knowledge about students' understanding and performance that influence teachers' instruction into four different categories as follows: Students' conceptual understanding, students' difficulties, students' reaction and perception and students' profiles.

4.2.1 Students' conceptual understanding. It refers to teachers' knowledge and understanding on students' conceptual knowledge and knowledge gaps. Four teachers [T1, T4, T5, T6] reflect their knowledge regarding the conceptual understanding of students. Teachers discussed the subject related concepts and the CT related concepts separately. Regarding the students' understanding of the subject related concepts, the common view of four teachers is that students understood the subject more deeply in CT integrated lessons than the previous learning method. "The fact that there are no failures, that the average was slightly higher than usual, indicates that this way of working with the decision tree, they really had to read the book for it, otherwise they will not understand the facts yet, I was able to find quite well that they understood more than enough of it. The average was also quite high." [T4], "If you look at the group 7 level [of the cell division], I think they have learned enough for this year [...] I thought this [CT integration] might be a way to make this indeed more understandable for the kids." [T1], "The students generally have quite a lot of trouble with that [to understand climate related learning objectives] The penny does not drop quickly, and that often takes a lot of time. The learning objective was actually to do that in a special way [CT integration], and we did to make it clear." [T4] With respect to students' understanding of the CT-related concepts, teachers explained that students have a clear understanding about it even some of students live difficulties. "Everyone had programmed something in Scratch, they could do that quite well. No matter how basic it was. Programming in Scratch and making the connection between the steps you have to take in Scratch, well I thought that went pretty quickly." [T1], "I think most of them, 80 to 90 percent knew what they were doing [...] it was not only Scratch but also biology." [T6]

4.2.2 Students' difficulties. According to teachers, students experience different sorts of problems during the lessons, including: understanding the programming concepts (conditions, design of algorithm, decision tree) [T1, T2, T4], required a lot of skill/knowledge to accomplish task (such as subject knowledge, programming knowledge, collaboration skill, planning skills etc.) [T3], creating new things [T5], understanding instruction [T6]. "They [students] found it very difficult to get conditions for cell division to actually get there [...] They did not progress beyond one condition to achieve cell division." [T1], "They found the assignment more difficult to design a short algorithm for the sensors. They just had to write that down. I noticed that they found that very difficult actually. They had a lot of trouble with that." [T2], "There is a lot of required skill you need to know besides the English stuff. You also need to make a plan, to be able to work together and also then the whole Scratch such as how you program those things. So, it required a lot of skills that have to come together to create something. I guess that was the hardest part for them". [T3], "They really had some difficulty with the concept of decision tree, because I had introduced it fairly quickly." [T4]

4.2.3 Students' profiles. It categorizes the teachers' knowledge on students' profiles, including: different backgrounds of programming [T4, T5, T6] and intelligence level of students [T4]. "Four groups have made their own program, and they come from an elementary school where computational thinking in the form of programming, code.org and Scratch was used, so they got their material and ideas from there [...] Those students did it all, that was very special." [T4] "Children have many different types of basic level [of programming]. Some had already worked quite a lot with Scratch, others not." [T5] "The type of students that I have are smart students, it is secondary school plus, students who are very sensitive to this kind of thing quickly. That is why it is extremely suitable for these students to also make this as a lesson component." [T4]

4.2.4 Students' reaction and perception. It involves teachers' knowledge and awareness of students' reactions and perceptions toward CT integration lessons. All teachers stated that students' perceptions were encouraging and positive, they told that with these key words: like, enjoy, enthusiastic, exciting, interesting, fun, educational, voluntarily [T1, T2, T3, T4, T5, T6]. One teacher [T4] noticed that two girls who went to the same primary school, and they indicated that they didn't like it. "I saw that they were working on it with enthusiasm." [T1] "They enjoy working with such a robot. It is often new to them too. They often get excited about that anyway." [T2] "A lot of them said that they liked it a lot. They thought it was hard but they said that was interesting in their opinions. I think they 
did enjoy." [T3] "You can really see that they have a lot of work on it but they also seemingly had a lot of fun doing it" [T4] "A whole group actually got to work very fanatically to remix it." [T5] "I do have the feeling that it has been educational and fun." [T6]

\subsection{Knowledge about Instructional Strategies (M3)}

We identified the teachers' knowledge about instructional strategies (IS) associated with integrating CT to lessons into two different categories: standard instructional strategy used to teach the relevant subject by default, new instructional strategy used to teach the same subject in a CT integrated lesson.

4.3.1 The standard and the CT integrated instructional strategies. We categorized the standard instructional activities including: mix of active learning methods, problem-based learning, direct instruction, explorative and experiential learning activities. We classified the CT integrated instructional activities as follows: experiential learning, problem-based learning, digital storytelling, explorative learning. As seen the comments of teachers in the Table 3, direct instruction or problem-based learning activities are emphasized as the standard teaching method, while the experiential learning activities are underlined mostly for the CT integrated lessons.

4.3.2 The overview of the standard and CT integrated instructional activities. It considers the similarities and differentiations between the standard instructional activities and the CT integrated instructional activities to teach the relevant subject.

(1) Go deeper in subject with CT integrated lessons: "This lesson series with computational thinking was actually a reason for us to go deeper into the subject content. I think we talked about that at a much lower-level last year. I thought this [CT integration] might be $a$ way to make this indeed more understandable for the kids. They haven't had that before. [...] The standard method does not get that far." [T1]

(2) Better understanding of the subject-context: "The fact that there are no failures in the test, that the average was slightly higher than usual, indicates that this way of working with the decision tree, they really had to read the book for it, otherwise they will not understand the facts yet [...] The average was also quite high." [T4]

(3) Using the power of digital technologies to show learning outcomes: "Look earlier, you used to have fewer ways for processing. Then it was often written or presenting or visual in the form of a drawing or that the children had to make a work of art and nowadays you have a lot of possibilities to show whether something has been learned. It can also be in the form of a video, podcast or algorithm. Or by designing something that can be printed out by a 3D printer. So, you have many more processing options, but in the end, it depends of course on what the teacher offers." [T2]

(4) More skills are required: "The biggest difference is that more skill is required. The standard one is isolated to the grammar and the vocabulary but with this the whole planning and working together becomes one so that makes it more challenging for the students." [T3]
Table 3: The overview of instructional activities

\begin{tabular}{|c|c|c|}
\hline C & $\begin{array}{l}\text { Standard instructional activ- } \\
\text { ities }\end{array}$ & $\begin{array}{l}\text { CT integrated instructional } \\
\text { activities }\end{array}$ \\
\hline T1 & $\begin{array}{l}\text { Mix of active learning meth- } \\
\text { ods and problem-based } \\
\text { learning: "I always make a mix } \\
\text { of roughly what is in the method } \\
\text { and then usually I make my own } \\
\text { lesson from it [...] I often try to } \\
\text { stimulate them; we had a lesson } \\
\text { about air. And then I talked about } \\
\text { how much air is actually pressing } \\
\text { on their body." }\end{array}$ & $\begin{array}{l}\text { Experiential learning and } \\
\text { difficult in practice: "Children } \\
\text { have to depict that in an anima- } \\
\text { tion or a movie or a game. Most } \\
\text { of the time it was animations } \\
\text { what I saw. [...] We tried that, } \\
\text { but it was difficult in practice. } \\
\text { They did not progress beyond one } \\
\text { condition to achieve cell division." }\end{array}$ \\
\hline T2 & $\begin{array}{l}\text { Sorting digital tools/ re- } \\
\text { sources and problem-based } \\
\text { learning: "[While teaching eth- } \\
\text { ical dilemmas], I've also talked } \\
\text { about algorithms from YouTube. } \\
\text { I think these kinds of ethical } \\
\text { dilemmas are very important } \\
\text { to discuss with children. But it } \\
\text { can also go further than talking } \\
\text { about philosophical questions. } \\
\text { For example, can an algorithm be } \\
\text { racist?" }\end{array}$ & $\begin{array}{l}\text { Experiential and problem- } \\
\text { based learning: "They deal } \\
\text { with ethical dilemmas about } \\
\text { self-driving cars. There is an } \\
\text { emergency; which situation } \\
\text { should the car choose? Is that } \\
\text { for the three older people who } \\
\text { walk on the left or is it for the } \\
\text { child who only walks on the } \\
\text { right. Which way should the } \\
\text { car swerve? There are questions } \\
\text { that programmers also deal with } \\
\text { when dealing with self-driving } \\
\text { cars." }\end{array}$ \\
\hline
\end{tabular}

T3 Direct instruction: "The stan- Experiential learning and dard way that I used is direct in- digital storytelling: "This time struction method so I do explicit we teach it with a digital story teaching vocabulary and what we you would need to plan and do is we teach them grammar create the story based on creating then we do a test at the end basi- an algorithm for that story to be cally." complete basically."

T4 Problem-based learning: " $B y$ Experiential and problemdefault, I actually treat each cli- based learning: "My idea mate separately based on a pic- would be much more of how ture, then I ask students if it would can you do things, because by be warm here, [...] then they doing you can also learn, and eventually come to the conclusion by saying, figuring out, drawing that if it is warm or humid, [...] your own conclusions, I think I try to get students to come to that computational thinking is a such a conclusion on the basis of very nice way to ask questions in questions." a different way."

T5 Explorative and experiential Experiential and explorative learning: "I often did by running learning: "In this case I did it around the schoolyard and cy- locally with a ruler, so reaction cling. Draw a line with the bikes speed, and that's actually the and then see how hard you can most practical thing you can do break, and whether it matters how with this. Very insightful in terms fast you cycle. For example, to of people what they can influence measure speed, or to watch cars themselves and not ..." outside, what do you see happening here?"

T6 Direct instruction: "Normally Experiential and explorative I do it fairly classically, usually learning: "It's different, more first a small movie or something, discovering. [...] They had some two or three minutes, no longer, assignments, there was a proand then I usually also give it on gram, they got to work on that, the blackboard. What I always do they performed assignments on it, is I write it down but then I also and in the end, they had to change explain [...] That's kind of my parameters themselves. It was the standard." intention that they could also add certain add-ins there themselves." 


\subsection{Knowledge about Ways to Assess Students' Learning and Performance (M4)}

We described teachers' knowledge about ways to assess students' understanding and performance using these codes: the assessment instruments (project, group discussions, rubric, presentation, test, practical assignment) and difficulties for assessment (observation, difficult nature of content). The assessment instruments and assessment processes teachers use in CT integrated lessons are classified as follows:

(1) Use formative (group discussions) and summative (projects) evaluation approaches together: "It was a clear assignment to program the remote sensor. You can see if the goal has been achieved by looking at the end result. If the program works then you can say that the end goal has been achieved. But also, in such a situation the process is even more important than the end result. So, what you try to do is walk around as much as possible and follow the conversations that the children have with each other, because I think working in collaboration at these kinds of assignments is important. [...] If you see that they are working so solution-oriented, you could say that the goal has been achieved." [T2]

(2) Rubrics for evaluating projects: "For the assessment part, I made a rubric and see how well they accomplished project. The rubrics include the content what you want to do: the grammar, speaking part because that was the extra part. They had to do voice overs. When it comes to creativity that's when I check like how did they actually make their stories. Are there any moving elements? How did the talking go? I check the algorithm part like how did you do that." [T3]

(3) Final presentation of the project and tests: "Students had to make two films about weather and climate, as a final presentation. One about the weather, how they predict the weather. Then they have to look at charts and look at old weather reports, try to find out what the weather is at next months. They had to present it. You could notice at all. [...] I listen to the message and it gives an indication of what they understand, what terminology they use. Furthermore, there will be a test, I will compile a grade from it." [T4]

(4) Practical assignment: "In this case I gave them an assignment in the booklet form that they had to fill in, that was a form of processing for them." [T5]

Teachers mentioned the difficulties principally in relation to the assessment of CT as follows:

(1) Difficult to measure all projects: "I find that very difficult to measure. Then I would really have to take a good look at all the projects as well. I had a little higher expectation about cell division, I would have liked them more correct, more consistent with reality [...] I think they have learned enough for this year." [T1]

(2) Difficult to observe in crowded class: "The point is, you have 25 kids in the class. Ideally you would sit at the table with a group of children to see how the communication between the children is going. So that you can adjust a bit here or there. But that is difficult when you have so many children in the classroom." [T2]

(3) Difficulties with assessment of CT related-learning objectives: Almost all teachers focused on evaluating subject- specific goals of lessons, nobody described the ways or strategies of assessment for CT-related goals.

\subsection{Teachers' Perceptions about CT Integrated Lessons}

We categorized the teachers' perception with respect to CT integrated lessons into three different categories: benefits of CT integration for students, benefits for teachers and attitude toward future usage of CT integration.

4.5.1 Benefits of CT integration for students. The focus of this category is mainly on how CT promotes the students' understanding and the advantages of CT integration for students.

(1) Learning by doing/ applying: "If you have learning by answering questions, they just remember, etc. Then this is not the right way. We work with "Remember - Understand -Integrate - Apply". But if you have to apply or integrate it, I think they will get further with this. It seems to me that students can actually apply it, it is above remembering or understanding." [T6] Similarly, T5 and T4 emphasized the importance of experiential learning.

(2) Add value to students' learning \& teach problem solving steps: "One of students said that it [cell division] also happens in my body because I am still growing. I think that's enough. I think it has added value. You force children to think about how you should work towards a certain goal. I think it is very valuable for children. Solving that problem in steps, that you teach them that, regardless of the problem." [T1]

(3) CT integration is necessary for my subject: "If you want to experience geography, you want to take it as a profession, then CT is a part, about searching and evaluating them, and the complexity of the whole, how can you do that better and then I think that digitally literate students are absolutely necessary for my subject." [T4]

4.5.2 Benefits of CT integration for teachers. This category emphasizes the points which are seen as advantages for teachers.

(1) Workload of teachers: "I did a lot less about it than before, they really did it themselves while learning." [T4] On the other hand, another teacher told that "The students really enjoyed with it but it was a lot of organizing [...] it costs a lot of energy." [T3]

(2) Students are more skilled at programming than teacher's expectation: "I thought it was very useful, because it was an eyeopener for me, actually there are already so many talents in students that they have learned at PL, we can use so much there. It is good to make everyone uniform, then you see what is happening in the classroom and what children are able to make and are capable of, they are much more skilled at things than my expectations." [T5]

(3) Practical / simple way for teaching: "Like this model, I find it very practical, because for something simple content, like distance, this is very interesting. I would also like to see how you can achieve the leverage content in Scratch." [T5]

4.5.3 Attitude toward future usage. It includes that how this implementation process affects teachers' perceptions about future plans for CT integration.

(1) Continue to use: "I will always continue to use it because I actually did it already, but not so clearly. I would almost say put that in your book from now on, I would say to the publishing house use these kinds of tricks because it is quite difficult content." [T4], "I found that adjusting the parameters and playing with them are very interesting as a basic step. When children are skilled enough and have enough brain capacity to use this form of abstraction, that you can 
continue to use." [T5], "It is well intended. I will still do these lessons more often" [T6].

(2) Share experience with colleagues: "I'm going to share it with my colleagues about what I've done. And whether they might have ideas about it or whether they might want to try it." [T1], "We have coding in our school and the coding teacher was very enthusiastic seeing them work like that... He said for next year he wants to collaborate." [T3]

(3) Follow-up lessons: "If you really start looking at a continuous learning line, then as a follow-up lesson I would treat those algorithms in writing $[. .$.$] because I have seen that they find that difficult."$ [T2] "I do have an idea, a kind of sequel what you could do based on the content of this part. [...] It would be nice to come up with something, especially in the future, where the students can program in any language or environment with very small steps and be able to do it themselves. So that they can do this in very small steps" [T4]

(4) Alternative examples for integration: "You can also use computational thinking, for example taking a tour of your own village" [T4], "I would also like to see how you can achieve the leverage context in Scratch. These are actually very simple physical principles that lend themselves extremely well to working with them in a very simple way." [T5]

\subsection{Barriers \& Suggestions for Implementation of Lessons}

For improving the CT integration process, we examined the implementation process of these case studies by analyzing the practical difficulties and improvement suggestions of teachers.

4.6.1 Practical difficulties. It refers to lack of time, lack of technical knowledge, organization related problems and COVID related difficulties.

(1) Lack of time: "We should have had a little more time. And I didn't really know the group well enough to deal with the situation" [T1]

(2) Organizing technical equipment and classroom: Almost all teachers [T1,T2,T3,T5,T6] mentioned the technical problems such as computers, internet connection, etc. "I think it was mainly about the organization, also arranging the laptops and the groups. If you need computers, you have to arrange a lot and they have to be brought back and it is not easy." [T1] "Problems that's always a bit cliché. When you work with technology, you always run into something not working or the batteries are empty. So, it takes a lot more time to prepare.” [T2]

(3) Programming knowledge of teachers: Almost all teachers believe that they should be more knowledgeable about programming [T1,T2,T3,T5]. "I guess that as a teacher I would be more knowledgeable whatever program you are going to use in order to guide the students better. At this time, I compensated that by using elder students." [T3]

(4) Organizing paper works: "That is what made it a bit difficult in the beginning to get that organization done. That is also because the research is, and not 100 percent lesson, normally I would have such a lesson less paper shop, maximum one piece of paper and no more." [T6] "It was a lot of organizing; it costs a lot of energy." [T3]

(5) COVID related issues: "You also have to deal with Corona, because with no corona it is much easier to go outside with them, which I often did with them" [T5]. Similarly T6 and T1 thought that students have the lack of motivation because of the COVID related issues.

4.6.2 Improvement suggestions. (1) Need of more preparation: "There is al ways room for more preparation [T1], “... the whole planning could be better. I think I could have done better by giving them the tools that they can actually plan everything better, I can give them more detailed steps." [T3]. And T5 stated that if he had put more time to think about it, it might have reached a slightly higher level.

(2) Content related improvements: "I think that if I did it again, I would choose something more for what children already understand more, I think that if they know more about the subject, programming will also be easier." [T1], "I just said maybe give some more examples of algorithms. I also find it difficult." [T2], "You would also prefer to appeal to the children's own creativity. That you delineate the assignment a little less and that you give the children a little more opportunity to come up with different solutions. They had to work reasonably towards a certain solution here." [T2]

(3) Self-improvement of teachers: "I do think that in order to do it well I need to up my level of computational thinking and programming in general to be able to design good assignments for them." [T3], "I would like to know more about the didactic of CT" [T6], "I would like to take programming course, because I sometimes notice that the students are better." [T6], "Teachers have a great need for the translation into practice. Do not stay theoretical for too long, but mainly go towards that practice." [T2].

\section{DISCUSSION}

There has been a growing need to prepare teachers to acquire the knowledge and skills required for integrating CT within the K-12 curriculum. A critical step in successful integration is assisting teachers in developing a knowledge of CT and how it connects to their curricular context. To this end, we conducted six different case studies in primary and secondary schools, we design CT related concepts and practices integrated to disciplinary content and pedagogical strategies to promote meaningful student outcomes in specific contexts. At the end of lesson series, we interviewed with teachers to understand their PCK on CT integration into disciplinary context, their perceptions and beliefs about CT, and difficulties they encountered during the CT integrated lessons.

\subsection{PCK on CT Integration into Context}

With respect to the knowledge about goals and objectives, after the lessons were carried out, teachers explained the subject-related objectives of lessons properly. Regarding to CT-related objectives of lessons, it is noticeable that all teachers emphasized only CT concepts which include the technology activities as learning goals. None of teachers explained CT learning objectives which based on CT practice (such as abstraction, algorithmic thinking, decomposition etc.) or CT perspectives (understandings about the technological world around them). Teachers did not indicate knowledge of combining content, instructional strategies and computing tools to foster students' CT competencies or even when they did, participants were unable to recognize and elaborate on those connections. Similarly, Mouza et al.[16] reported that the ability to weave knowledge of CT concepts, computing tools and practices with content and pedagogy varied among participants. While a number 
of pre-service teachers were able to design and enact lessons that seamlessly integrated content, pedagogy and computing tools to foster students' CT knowledge and skills, others focused broadly on uses of computing tools and problem-solving descriptions [16]. The reason behind this problem might be associated with the courses are typically disconnected from the teaching theories and methods pre-service teachers learn in other education courses, focusing instead on technology [15]. To alleviate this problem, educational technology courses or in-service trainings can be revised to give teachers opportunities to think computationally and experience computational thinking as a generic set of skills and competencies that are not dependent on computers or other forms of educational technology [30].

Regarding to knowledge about students' understanding and performance, we categorized them as students' conceptual understanding, students' difficulties, students' reaction and perception and students' profiles. The common view of teachers is that students were able to dive more deeper in the subject-related context via CT integrated lessons compared to their standard manner of teaching the same subject matter, i.e., without employing CT. With respect to students' difficulties, they mainly emphasized that students have lack of prior knowledge about programming concepts and apart from technical skills other many different skills were required for completing the tasks such as organization, planning, collaboration etc. Students' programming competencies are not required for the integration of CT into school curricula, despite the fact that CT is linked to programming. However, the present focus on helping kids in transitioning from "consumers" to "creators" of computing technologies may benefit from the use of programming tools [16]. As overall, all teachers stated that students' reactions and perceptions were encouraging and very positive.

In connection with knowledge about instructional strategies, Teachers were asked to compare the standard and CT integrated instructional activities to teach the same school subject. They pointed out that students can go deeper in the subject-context and understand better in CT integrated lessons compared to standard way of teaching. Students were able to use the power of digital technologies for processing the subject related content. Teachers mainly emphasized the direct instruction or problem-based learning strategies as the standard teaching method, while they underlined mostly the experiential, explorative and problem-based learning strategies for the CT integrated lessons. Similarly, Hsu et al. [11] reported that problem-based learning and project-based learning are the highest ranked instructional strategies in CT studies. There is lack of knowledge about different instructional strategies which used specifically to help students improve their subject-related and CTrelated performance through $\mathrm{CT}$ activities, e.g., use-modify-create strategy.

In terms of knowledge about assessment strategies, teachers prefer to use different instruments for evaluating the subject-specific learning outcomes such as project, group discussions, rubric, presentation, test, practical assignments. They find difficult to evaluate with projects or observation in the crowded class. None of teachers described the ways or strategies of assessment for CT-related goals. These findings are parallel with the researches in literature, because it is still challenging to reach a comprehensive understanding of how to assess students' CT and there is a lack of reliable and valid common CT assessment instruments that can be applicable across all platforms and devices in order to compare students' CT performance under varied conditions [23].

\subsection{Teachers' Perceptions about CT Integrated Lessons}

Teachers discussed the benefits of CT integration and they shared their intentions regarding the future usage. They believed that CT integrated lessons add value to students' learning and it's important for students to learn the steps of problem solving. They found useful the constructivist approach that formed the basis of the all lessons, particularly to deepen in the subject related content by applying/using technical skills with hands-on activities. The degree of autonomy that students have in making decisions about their produced artefacts was seen as a significant factor to consider when assessing learners' ability to engage in constructionist learning in computational thinking activities [7].

\subsection{Barriers and Suggestions for CT Integrated Lessons}

The teachers explained the problems they faced during the CT integrated lessons and their suggestions to solve these problems and improve the lessons. They refer to lack of time, lack of technical knowledge of teachers and students, difficulties with organization of equipment and class. It is remarkable that teachers feel that they do not have the qualities and abilities necessary for programming and they desire to be more knowledgeable about programming concepts and CT related pedagogical aspects. Integrating computational thinking in $\mathrm{K}-12$ education requires teacher educators to prepare teachers to provide teachers with the content, pedagogy, and instructional strategies needed to incorporate computational thinking into their curricula and practice in meaningful ways, enabling their students to use its core concepts and dispositions to solve discipline-specific and interdisciplinary problems [30]. It is important to take steps in this direction.

They explained the difficulties caused by COVID. Because the experiments were carried out during the period when there were many COVID restrictions at schools. There was an effort to maintain social distance especially between high school students. It was also a period when school trips and out-of-school activities were not possible. Because of COVID related issues, one teacher had to do his lessons as online. So, teachers couldn't design their lesson plans as they wish, they said that it was a kind of difficulty for them. It was also a limitation for the research.

\section{CONCLUDING REMARKS}

Empowering all grade and all disciplines teachers with valid information about CT provides an opportunity that could inspire students to explore different disciplines with a computing perspective. This paper will be of benefit to researchers and all teachers who desire to design and conduct their own CT integrated lessons and to explore the ways for creating a new teacher education curriculum including CT approaches. As we discussed before, this study is a part of a larger project [2] which aims to generate a set of empirically validated design principles for learning activities fostering CT development within the curriculum. Future work will 
describe the students' understanding with respect to subject related and $\mathrm{CT}$ related objectives gained by in these CT integrated lessons. Also, there will be the second development cycle of the lessons, the activities will be improved according to teachers' suggestions and students' feedback, then the updated learning activities will be tested one year later. The teachers' PCK development will continue to be monitored and analyzed in terms of content and coherence [16]. We will look for differentiating features of the teachers' development, with the purpose of typifying individual development processes. In the light of the PCK framework, future research should continue to investigate the ways for integrating CT knowledge and skills into teacher education curricula, as well as extracting the type of knowledge required to transform tools used in creating computational artifacts into meaningful educational experiences for $\mathrm{K}-12$ learners.

\section{REFERENCES}

[1] Charoula Angeli, Joke Voogt, Andrew Fluck, Mary Webb, Margaret Cox, Joyce Malyn-Smith, and Jason Zagami. 2016. A K-6 computational thinking curriculum framework: Implications for teacher knowledge. Fournal of Educational Technology \& Society 19, 3 (2016), 47-57.

[2] Erik Barendsen. 2022. In progress. Computational Thinking in context: a teaching and learning trajectory for primary and secondary education. NRO, Netherlands.

[3] Erik Barendsen and Ineke Henze. 2019. Relating teacher PCK and teacher practice using classroom observation. Research in Science Education 49, 5 (2019), 11411175 .

[4] Valerie Barr and Chris Stephenson. 2011. Bringing computational thinking to $\mathrm{K}-12$ : what is Involved and what is the role of the computer science education community? Acm Inroads 2, 1 (2011), 48-54.

[5] Matt Bower and Katrina Falkner. 2015. Computational Thinking, the Notional Machine, Pre-service Teachers, and Research Opportunities. ACE, . 37-46 pages.

[6] Karen Brennan and Mitchel Resnick. 2012. New frameworks for studying and assessing the development of computational thinking. In Proceedings of the 2012 annual meeting of the American educational research association, Vol. 1. AERA, Vancouver, Canada, 25.

[7] Andrew Csizmadia, Bernhard Standl, and Jane Waite. 2019. Integrating the constructionist learning theory with computational thinking classroom activities. Informatics in Education 18, 1 (2019), 41-67.

[8] Judith Gal-Ezer and Chris Stephenson. 2010. Computer science teacher preparation is critical. ACM Inroads 1, 1 (2010), 61-66.

[9] Susanne Hambrusch, Christoph Hoffmann, John T Korb, Mark Haugan, and Antony L Hosking. 2009. A multidisciplinary approach towards computational thinking for science majors. ACM SIGCSE Bulletin 41, 1 (2009), 183-187.

[10] David Hemmendinger. 2010. A plea for modesty. Acm Inroads 1, 2 (2010), 4-7.

[11] Ting-Chia Hsu, Shao-Chen Chang, and Yu-Ting Hung. 2018. How to learn and how to teach computational thinking: Suggestions based on a review of the literature. Computers \& Education 126 (2018), 296-310.

[12] Peter Hubwieser, Johannes Magenheim, Andreas Mühling, and Alexander Ruf. 2013. Towards a conceptualization of pedagogical content knowledge for computer science. In Proceedings of the ninth annual international ACM conference on International computing education research. ., ., 1-8.

[13] Ioannis Ioannou and Charoula Angeli. 2015. Technological pedagogical content knowledge as a framework for integrating educational technology in the teaching of computer science. In Technological pedagogical content knowledge. Springer, ., 225-237.

[14] Shirley Magnusson, Joseph Krajcik, and Hilda Borko. 1999. Nature, sources, and development of pedagogical content knowledge for science teaching. In Examining pedagogical content knowledge. Springer, ., 95-132.

[15] Punya Mishra and Matthew J Koehler. 2006. Technological pedagogical content knowledge: A framework for teacher knowledge. Teachers college record 108, 6 (2006), 1017-1054.

[16] Chrystalla Mouza, Hui Yang, Yi-Cheng Pan, Sule Yilmaz Ozden, and Lori Pollock. 2017. Resetting educational technology coursework for pre-service teachers: A computational thinking approach to the development of technological pedagogical content knowledge (TPACK). Australasian fournal of Educational Technology 33, 3 (2017), ?-?

[17] Seymour Papert. 1996. Computers in the classroom: Agents of change. The washington post education review 27 (1996), ?

[18] Alex Ruthmann, Jesse M Heines, Gena R Greher, Paul Laidler, and Charles Saulters. 2010. Teaching computational thinking through musical live coding in scratch. In Proceedings of the 41st ACM technical symposium on Computer science education.
., ., 351-355.

[19] Cynthia Selby and John Woollard. 2013. Computational thinking: the developing definition. E-prints ? (2013), ?

[20] Pratim Sengupta, John S Kinnebrew, Satabdi Basu, Gautam Biswas, and Douglas Clark. 2013. Integrating computational thinking with K-12 science education using agent-based computation: A theoretical framework. Education and Information Technologies 18, 2 (2013), 351-380.

[21] Lee S Shulman. 1986. Those who understand: Knowledge growth in teaching. Educational researcher 15, 2 (1986), 4-14.

[22] Anselm Strauss and Juliet Corbin. 1990. Basics of qualitative research. Sage publications, .

[23] Kai-Yu Tang, Te-Lien Chou, and Chin-Chung Tsai. 2020. A content analysis of computational thinking research: An international publication trends and research typology. The Asia-Pacific Education Researcher 29, 1 (2020), 9-19.

[24] Jan H Van Driel and Amanda Berry. 2012. Teacher professional development focusing on pedagogical content knowledge. Educational researcher 41, 1 (2012), $26-28$.

[25] Joke Voogt, Petra Fisser, Jon Good, Punya Mishra, and Aman Yadav. 2015. Computational thinking in compulsory education: Towards an agenda for research and practice. Education and Information Technologies 20, 4 (2015), 715-728.

[26] David Weintrop, Elham Beheshti, Michael Horn, Kai Orton, Kemi Jona, Laura Trouille, and Uri Wilensky. 2016. Defining computational thinking for mathematics and science classrooms. Fournal of Science Education and Technology 25, 1 (2016), 127-147.

[27] Michael Philetus Weller, Ellen Yi-Luen Do, and Mark D Gross. 2008. Escape machine: teaching computational thinking with a tangible state machine game. In Proceedings of the 7th international conference on Interaction design and children. ., ., 282-289.

[28] Jeanette Wing. 2011. Research notebook: Computational thinking-What and why. The link magazine 6 (2011), 20-23.

[29] Jeannette M Wing. 2006. Computational thinking. Commun. ACM 49, 3 (2006), 33-35.

[30] Aman Yadav, Sarah Gretter, Jon Good, and Tamika McLean. 2017. Computational thinking in teacher education. In Emerging research, practice, and policy on computational thinking. Springer, ., 205-220.

[31] Aman Yadav, Hai Hong, and Chris Stephenson. 2016. Computational thinking for all: Pedagogical approaches to embedding 21st century problem solving in K-12 classrooms. TechTrends 60, 6 (2016), 565-568.

[32] Hui Yang, Chrystalla Mouza, and Yi-Cheng Pan. 2018. Examining pre-service teacher knowledge trajectories of computational thinking through a redesigned educational technology course. In . International Society of the Learning Sciences, Inc.[ISLS]., . 